Communication

\title{
Combination of CTec2 and GH5 or GH26 Endo-Mannanases for Effective Lignocellulosic Biomass Degradation
}

\author{
Samkelo Malgas * (D) and Brett I. Pletschke \\ Enzyme Science Programme (ESP), Department of Biochemistry and Microbiology, Rhodes University, \\ Grahamstown 6140, Eastern Cape, South Africa; b.pletschke@ru.ac.za \\ * Correspondence: samkelomalgas@yahoo.com or s.malgas@ru.ac.za; Tel.: +27-46-603-8010
}

Received: 23 September 2020; Accepted: 9 October 2020; Published: 16 October 2020

check for updates

\begin{abstract}
Among endo-mannanases, glycoside hydrolase (GH) family 26 enzymes have been shown to be more catalytically active than GH5 enzymes on mannans. However, only GH5 endo-mannanases have been used for the formulation of enzyme cocktails. In this study, Bacillus sp.-derived GH5 and GH26 endo-mannanases were comparatively analysed biochemically for their synergistic action with a commercial cellulase blend, $\mathrm{CTec} 2$, during pre-treated lignocellulose degradation. Substrate specificity and thermo-stability studies on mannan substrates showed that GH26 endo-mannanase was more catalytically active and stable than GH5. GH26 also exhibited higher binding affinity for mannan than GH5, while GH5 showed more affinity for lignocellulosic substrates than GH26. Applying the endo-mannanases in combination with $\mathrm{CTec} 2$ for lignocellulose degradation led to synergism with a 1.3-fold increase in reducing sugar release compared to when CTec2 was used alone. This study showed that using the activity of endo-mannanases displayed with model substrates is a poor predictor of their activity and synergism on complex lignocelluloses.
\end{abstract}

Keywords: CTec2; endo-mannanase; lignocellulose; mannan; synergism

\section{Introduction}

Lignocellulosic biofuel and bio-based platform chemical production involves the processes of biomass pre-treatment, enzymatic saccharification, microbial fermentation and product isolation via distillation, and one of the major factors affecting its techno-economic feasibility is the biomass recalcitrance to enzymatic saccharification. One way to tackle the challenge is to improve the hydrolytic efficacy of "cellulase" mixtures by optimising the cooperation among cellulases and various accessory enzymes such as hemicellulases [1-3]. However, in this regard, studies have predominantly been conducted on cellulase-xylanase synergism effects, with fewer studies conducted on cellulase to mannanase synergism.

Endo-mannanases (EC 3.2.1.78) initiate the degradation of mannans by randomly cleaving the backbone to liberate short $\beta-1,4$-mannooligomers and produce new chain ends; this class of enzyme is found in glycoside hydrolase (GH) families 5, 26, 113 and 134 based on sequence similarity [4]. A few studies have shown that endo-mannanases synergistically improve the production of fermentable sugars during the degradation of lignocellulosic biomass, such as corn stalk and pineapple pulp [5], sugarcane bagasse [6-8] and softwoods $[9,10]$. However, these studies have mostly been conducted with GH5 endo-mannanases, and no studies have ever comparatively evaluated GH5 and GH26 endo-mannanases for agricultural residues saccharification improvement. It has been shown that GH26 endo-mannanases generally display higher activity on mannans, particularly galactomannans, compared to GH5 endo-mannanases, and as a result it has been proposed that GH26 endo-mannanases are more suitable for augmentation in enzyme cocktails [11,12]. 
Various agricultural and food processing residues, such as pineapple pulp and sugarcane bagasse, are generally lignocellulosic in nature, containing a complex lattice structure with close associations between holocellulose (combination of cellulose and hemicelluloses, mainly xylan and minor amounts of mannan) and lignin [5-8]. Thus, in order to completely hydrolyse these lignocellulosic biomass substrates into fermentable sugars, it is necessary to design an ideal enzymatic cocktail consisting of activities targeted at the various components comprising the holocellulose contained in these substrates.

With the aid of biochemical characterisation studies (substrate specificity, adsorption and thermo-stability), the aim of the study was to evaluate which GH family endo-mannanase (GH5 versus GH26) can perform better synergistically with a commercial cellulolytic preparation, Cellic ${ }^{\circledR}$ $\mathrm{CTec} 2$, during the degradation of pre-treated lignocellulosic biomass. On model mannan substrates (ivory nut linear mannan, konjak glucomannan and locust bean gum galactomannan), the GH26 endo-mannanase was more catalytically active than the GH5 endo-mannanase. Binding affinity studies showed that GH5 adsorbed more to lignocellulosic biomass than GH26, while GH26 adsorbed more to mannan than did GH5. However, during the synergistic degradation of lignocellulosic biomass, the two endo-mannanases performed similarly.

\section{Results and Discussion}

\subsection{Enzyme Specificity Studies}

The initial rate of hydrolysis of model mannan and cellulose substrates by the endo-mannanases (GH5 and GH26) and CTec2 was determined (Table 1).

Table 1. Specific activities ( $\mu \mathrm{mol} / \mathrm{min} / \mathrm{mg}$ protein) of the enzymes on model cellulosic and mannan substrates.

\begin{tabular}{ccccccc}
\hline \multirow{2}{*}{ Enzyme } & \multicolumn{3}{c}{ Model Mannan Substrates } & \multicolumn{2}{c}{ Model Cellulosic Substrates } \\
\cline { 2 - 7 } & Ivory Nut & Konjak & Locust Bean Gum & CMC-Na & $p$ NPC & $p$ NPG \\
\hline Cellic ${ }^{\circledR}$ CTec2 & 0.00 & 0.00 & 0.00 & 16.34 & 10.41 & 12.53 \\
GH5 mannanase & 38.21 & 45.58 & 29.26 & 0.00 & 0.00 & 0.00 \\
GH26 mannanase & 61.44 & 60.58 & 77.22 & 0.00 & 0.00 & 0.00 \\
\hline
\end{tabular}

Among the endo-mannanases, GH26 was more catalytically active on the mannans compared to GH5. Similarly, other studies have shown that GH26 endo-mannanases are generally more catalytically active on mannans compared to GH5 mannanases [11,12]. Additionally, and similar to our findings, BaMan5A, derived from Bacillus agaradhaerens, can accommodate glucose or mannose at both its -2 and +1 subsites, while a GH26 Bacillus subtilis endo-mannanase, BsMan26A, displays tight specificity for mannose at its negative binding sites; thus, BaMan5A is able to hydrolyse glucomannan in which the sequence of glucose and mannose is highly variable, while BsMan26A cannot [13]. This explains why GH5 in our study showed high activity on konjac glucomannan while GH26 showed lower activity on this substrate relative to other mannans. GH26 endo-mannanases were recently found to have a novel substrate degradation pattern on galactomannan, making them superior in their capability to degrade highly substituted galactomannans in comparison to GH5 endo-mannanases [12]. This capability seems to be due to the possibility of accommodating galactopyranosyl residues in both the $-1,-2$ and +1 subsites of at least some GH26 endo-mannanases [12]. This likely applies to the Bacillus-derived endo-mannanases used in this study. Both endo-mannanases exhibited no activity towards CMC-Na, $p$ NPC and $p$ NPG; the lack of activity in these substrates suggests that the enzymes possess no cellulolytic activities and are thus classical mannanolytic enzymes.

CTec2, on the other hand, did not exhibit any mannanolytic activity on either of the model mannans evaluated; similarly, CTec3 was reported to exhibit weak mannan-degrading activity [14]. High endo-glucanase activity (16.34 U/mg) on CMC-Na was reported for CTec2 (Table 1) and was expected, as CTec2 was reported to contain at least four endoglucanases-Cel5A, Cel7B, Cel12A and Cel61A [15]. CTec2 also displayed $10.41 \mathrm{U} / \mathrm{mg}$ of cellobiohydrolase I activity on $p$ NPC 
(Table 1), and this activity was expected as CTec2 contains a cellobiohydrolase I, Cel7A [16]. Finally, appreciable $\beta$-glucosidase activity was also recorded from $\mathrm{CTec} 2$, and this was no surprise as the enzyme cocktail contains Cel3A $[15,16]$.

\subsection{Enzyme Synergy Studies}

The Bacillus-derived endo-mannanases were then evaluated for their cellulase cocktail (CTec2)-boosting effect during the hydrolysis of delignified pineapple pulp and sugarcane bagasse (Figure 1). Cellic ${ }^{\circledR}$ CTec2 was chosen as the core enzyme cocktail, as it is known as a highly efficient cellulase and hemicellulase (xylanolytic activities) complex that ensures cost-efficient conversion of pretreated lignocellulosic materials to fermentable sugars under industrial conditions.
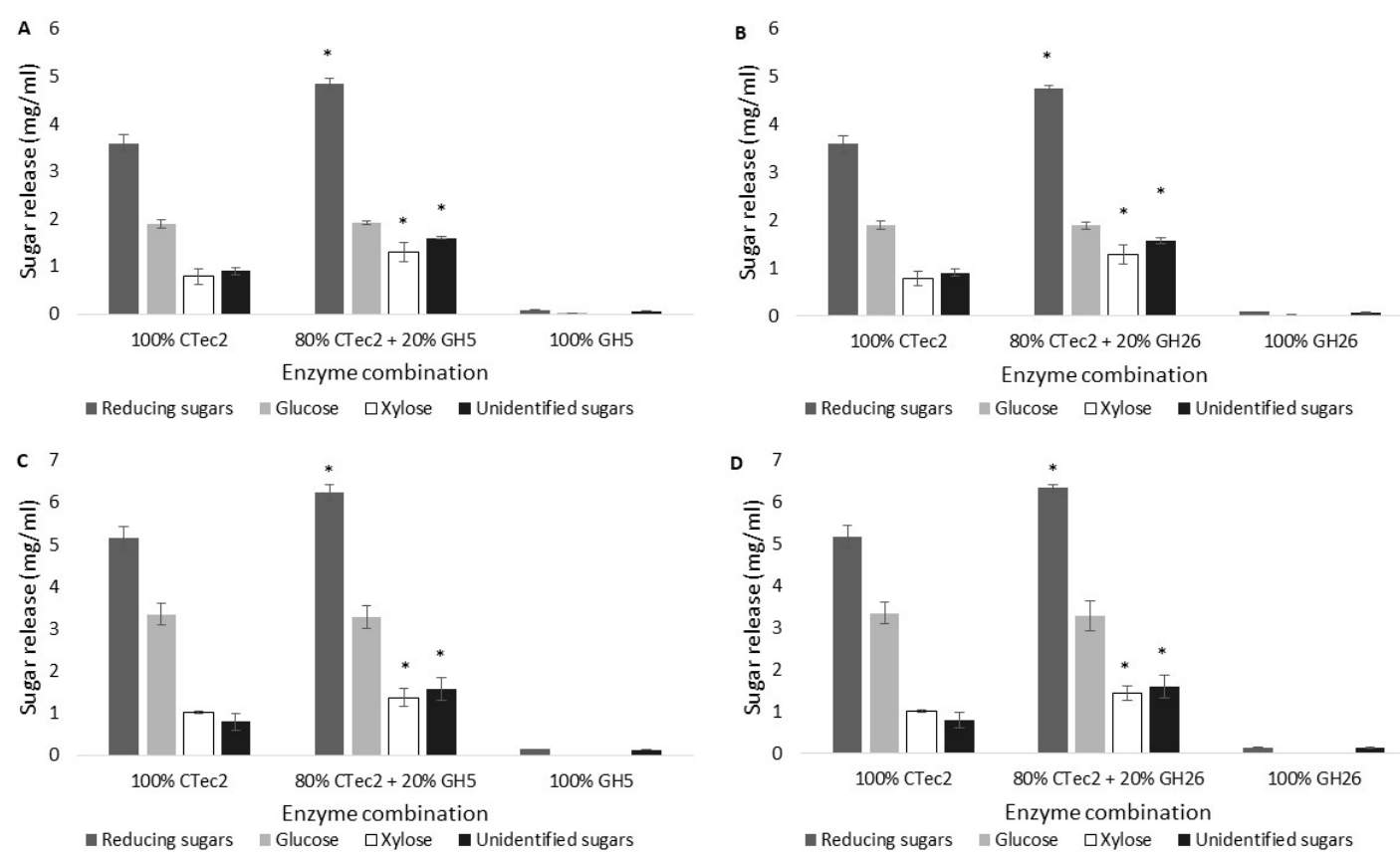

Figure 1. Holocellulose hydrolysis of delignified pineapple pulp by CTec2 with/without (A) GH5 or (B) GH26 endo-mannanase and delignified sugarcane bagasse by CTec2 with/without (C) GH5 or (D) GH26 endo-mannanase after $24 \mathrm{~h}$. All assays were performed in quadruplicate and are shown as mean values $\pm S D(n=4)$. Statistical analysis was conducted using one way ANOVA for assessing improvement of hydrolysis by the enzyme combinations compared to the single enzyme, CTec2. Key: $*(p<0.05)$.

The two endo-mannanases exhibited a similar boosting effect (1.3-fold increase in reducing sugar and xylose release) on lignocellulose hydrolysis (Figure 1). The addition of endo-mannanases to CTec2 did not improve glucose release from the lignocellulosic biomasses. This likely implies that mannan may be more intimately associated with xylan than glucan-hence the observed improvement in xylose release and no improvement in glucose release by the cellulase and xylanase-containing preparation, CTec2, in the presence of the endo-mannanases. Based on the data, it appears as if GH5 activity compares well with that of GH26, even though GH26 is catalytically more active on model mannan substrates. We suspect a carbohydrate binding module (CBM) may be assisting GH5 activity on lignocellulosic biomasses. Recently, it was shown that TresMan5A, a CBM-containing endo-mannanase, was superior to other tested GH5 and GH26 endo-mannanases during softwood saccharification, despite TresMan5A being among the catalytically slowest on purified mannan substrates [14]. 


\subsection{Endo-Mannanase Binding Affinity on Various Substrates}

As an example of heterogeneous catalysis, the rate at which enzymatic hydrolysis occurs is governed by the capacity of the enzyme (diffusing catalyst) to adsorb to the substrate (solid sorbent), allowing the enzyme's catalytic site to be in close proximity with the substrate's cleavage site $[17,18]$. Therefore, investigating the relationship between adsorption and mannan hydrolysis could potentially shed novel insights into understanding enzyme-substrate recognition and attack patterns of endo-mannanases, as well as their synergism with other enzymes during biomass hydrolysis.

The endo-mannanases displayed low comparable binding affinity for cellulose, while GH26 showed higher binding affinity for a model mannans compared to GH5, which showed higher binding affinity for the lignocellulosic substrates (Table 2). The GH5 endo-mannanase used in this study was from Bacillus circulans and possesses a family 59 CBM (UniProt ID: O66185) that was reported to bind efficiently to mannan, xylan and cellulose [19]. This may explain the high binding affinity of GH5 on other polysaccharides besides mannan. Some GH5 endo-mannanases were reported to typically having CBMs known to confer cellulose binding and to increase the mannan hydrolysis of lignocellulosic biomasses [20], leading to improved overall degradation [21]. The higher binding affinity of GH5 may explain why comparable boosting effects were displayed by the two endo-mannanases on CTec2 performance even though GH5 is catalytically less efficient than GH26.

Table 2. Mannanase binding affinity (\%) on model and pre-treated lignocellulosic substrates at $4{ }^{\circ} \mathrm{C}$.

\begin{tabular}{ccccc}
\hline Enzyme & Avicel PH101 & Locust Bean Gum & Pine Apple Pulp & Sugarcane Bagasse \\
\hline GH5 mannanase & 30.40 & 47.98 & 54.87 & 86.50 \\
GH26 mannanase & 32.77 & 58.04 & 37.76 & 53.61 \\
\hline
\end{tabular}

\subsection{Endo-Mannanase Thermo-Stability}

Another possibility for the comparable performance of the endo-mannanases on lignocellulosic biomasses is that hydrolysis might arise from the improved overall thermo-stability of GH5, allowing it to draw closer catalytically with GH26, since the lignocellulose hydrolysis was performed over a relatively long period of time ( $>24 \mathrm{~h}$ ). Thereafter, the thermo-stability of the GH5 and GH26 endo-mannanases was assessed over a period of $24 \mathrm{~h}$ at $50^{\circ} \mathrm{C}$ (Figure 2).

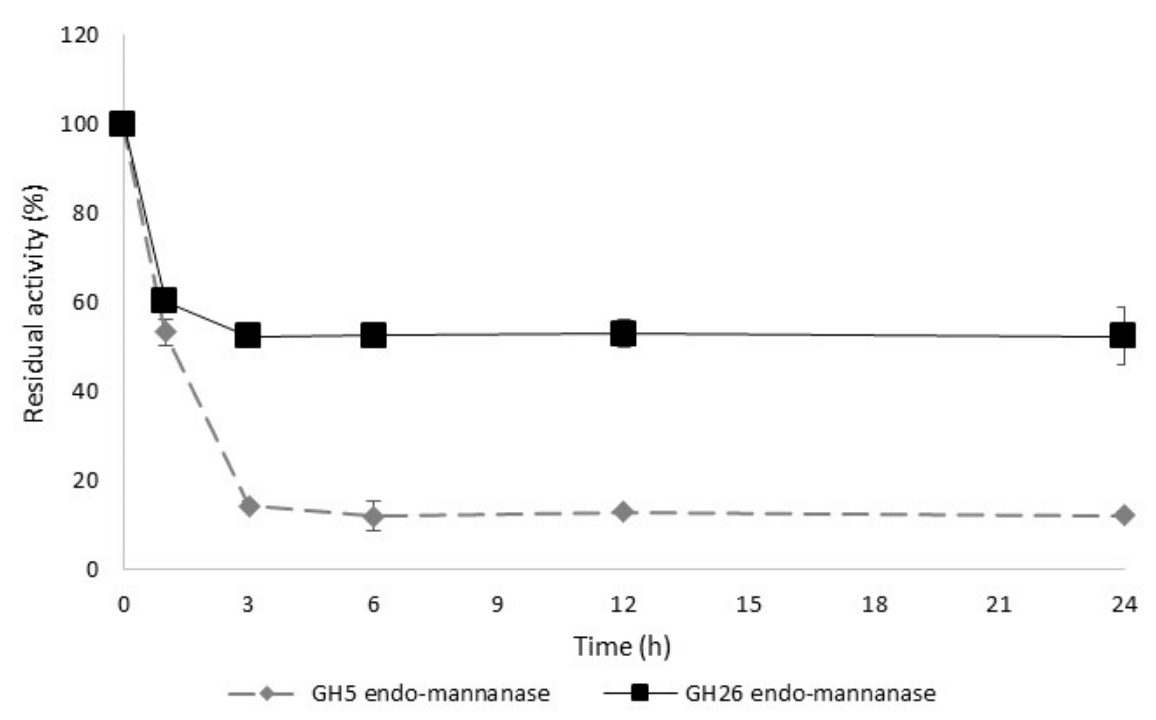

Figure 2. Endo-mannanase (GH5 and GH26) thermo-stability at $50{ }^{\circ} \mathrm{C}$. All assays were performed in quadruplicate and are shown as mean values $\pm S D(n=4)$. 
Our results showed that GH26 was more thermostable (it retained up to $50 \%$ activity after $24 \mathrm{~h}$ ) than GH5 (which retained about $10 \%$ activity during the same period) (Figure 2). Therefore, thermo-stability could not account for the comparable observed hydrolytic efficacies of the endo-mannanases when cooperating synergistically with the cellulase, CTec2. It is noteworthy to mention that the presence of the lignocellulosic biomass substrates could enhance the thermo-stability of both endo-mannanases during the time course of hydrolysis, as such findings have been reported for other glycoside hydrolases such as endo-xylanases [1]. Implications of this could be the improvement of residual GH5 endo-mannanase activity during the $24 \mathrm{~h}$ time course hydrolysis of the lignocellulosic biomass substrates.

\subsection{Endo-Mannanase Activity on Galactomannan-Cellulose Complexes}

Galactomannan-cellulose complexes were synthesised as described previously [22]. With $2 \%$ $(\mathrm{w} / \mathrm{v})$ of the galactomannan-cellulose complex used as a substrate, both endo-mannanases displayed lowered specific activities compared to those displayed on locust bean gum. GH26 activity was reduced by up to $75 \%(19.49 \mathrm{U} / \mathrm{mg})$, while only $50 \%$ activity reduction was observed for the GH5 (14.77 U/mg). This observation correlates with the difference in hydrolysis rate of the galactomannan-cellulose complex by the endo-mannanases to the binding and hydrolysis of the lignocellulosic biomass. This finding is in agreement with previous reports, which state that GH5 endo-mannanases are more catalytically efficient on insoluble/adsorbed mannans, whilst GH26 counterparts prefer soluble/free mannans $[13,23]$. To support this, a Trichoderma derived GH5 endo-mannanase containing a CBM1, TresMan5A, was shown to perform better than its CBM-truncated version during softwood degradation, while its CBM-truncated form generally performed better than six GH26 endo-mannanases, this being most likely due to the core modules of GH26 endo-mannanases not being as optimal as those of GH5 for the degradation of mannan associated with cellulose [14].

\section{Materials and Methods}

\subsection{Materials}

Two Bacillus sp.-derived endo-mannanases, GH5 (E-BMABC) and GH26 (E-BMABS), were purchased from Megazyme, Dublin, Ireland. The commercial cellulase preparation, Cellic ${ }^{\circledR}$ CTec2, was kindly donated by Novozymes Inc., Bagsvaerd, Denmark. All other chemicals were of reagent grade and were purchased from Sigma Aldrich, St. Louis, MO, USA. Sugarcane bagasse and pineapple pulp were selected as lignocellulosic substrates due to their importance in the South African agricultural sector. The sugarcane bagasse was kindly donated by Ushukela Milling (Pty) Ltd., Durban, South Africa. The pineapple pulp was prepared by homogenising chopped pineapples in a blender (Salton Inc., Chicago, IL, USA) until a fine pulp was produced, followed by draining all the juice with a cheese cloth, rinsing the residual pulp with distilled water and oven drying it at $50{ }^{\circ} \mathrm{C}$ until a constant mass was obtained.

\subsection{Lignocellulosic Biomass Pre-Treatment and Composition Analysis}

A total of $10 \mathrm{~g}$ of lignocellulosic biomass (pineapple pulp and sugarcane bagasse) was treated using sodium chlorite/acetic acid as described previously [24]. The wood biomass was characterised using the modified sulphuric acid method of the National Renewable Energy Laboratory-NREL [25,26] at the Department of Chemistry, Umeå University, Sweden. The chemical composition of the pretreated substrates is shown in Table 3.

Table 3. Chemical composition of delignified pineapple pulp and sugarcane bagasse.

\begin{tabular}{ccccccccc}
\hline \multirow{2}{*}{ Substrate } & \multicolumn{4}{c}{ Carbohydrates (\%) } & \multicolumn{3}{c}{ Lignin (\%) } & \multirow{2}{*}{ Ash } \\
\cline { 2 - 8 } & Glucan & Xylan & Arabinan & Mannan & Galactan & KL & ASL & \\
\hline Pineapple pulp & 32.5 & 22.8 & 3.5 & 1.5 & 2.5 & 4.6 & 4.7 & 2.5 \\
Sugarcane bagasse & 38.2 & 27.6 & 3.1 & 3.4 & 1.2 & 16.0 & 6.6 & 4.0 \\
\hline
\end{tabular}

Where $\mathrm{KL}$ is Klason lignin and ASL is acid soluble lignin. 


\subsection{Protein Content}

The protein contents of the endo-mannanases and CTec2 were determined by the Bradford method [27]. Bovine serum albumin (BSA) was used as a suitable protein standard.

\subsection{Enzyme Hydrolysis of Lignocellulosic Biomass}

The substrate specificities of the enzymes (CTec2, and GH5- and GH26 endo-mannanases) were determined under standard assay conditions $\left(50 \mathrm{mM}\right.$ sodium citrate buffer at $\mathrm{pH} 5.0,50{ }^{\circ} \mathrm{C}$ and under continuous agitation at $25 \mathrm{rpm})$ using $1 \%(w / v) \mathrm{CMC}-\mathrm{Na}$, ivory nut linear mannan, konjak glucomannan and locust bean gum galactomannan or $2 \mathrm{mM} p$-nitrophenyl derivatives ( $p$ NP- $\beta$-D-glucopyranoside $(p N P G)$ and $p$ NP- $\beta$-D-cellobioside ( $p$ NPC)). One unit (U) was defined as the amount of enzyme required to release $1 \mu$ mole of product per minute, under the assay conditions specified.

Delignified pineapple pulp and sugarcane bagasse biomass hydrolysis was carried out at a biomass loading of $2 \%(w / v)$ in $50 \mathrm{mM}$ sodium citrate buffer $(\mathrm{pH} 5.0)$ at $50{ }^{\circ} \mathrm{C}$, mixing at $25 \mathrm{rpm}$ for up to $24 \mathrm{~h}$. The enzyme loading was kept constant at $2.75 \mathrm{mg}$ protein/g of biomass. For enzyme synergism studies, cellulase replacement was performed by removing $20 \%$ of Cellic ${ }^{\circledR}$ CTec2 protein loading and replacing it with $20 \%$ of either GH5 or GH26 endo-mannanase.

\subsection{Analytical Methods}

Reducing sugar and $p$-nitrophenol released from polymeric and $p$-nitrophenyl derived substrates, respectively, were monitored as described previously [11]. For reducing sugar estimation, a 1:2 volume ratio of sample with DNS solution was prepared and heated at $100{ }^{\circ} \mathrm{C}$ for $8 \mathrm{~min}$, followed by wavelength reading at $540 \mathrm{~nm}$. Glucose or mannose were used as suitable standards for the DNS assay, depending on the polymeric substrate used. For $p$-nitrophenyl derived substrates, the released $p$-nitrophenyl product was monitored at $405 \mathrm{~nm}$. Quantification of glucose and xylose in the lignocellulose hydrolysates was performed as described previously [24] by the glucose oxidase/peroxidase (GOPOD) method (K-GLUC, Megazyme) and enzymatically (K-XYLOSE, Megazyme) with a 20 min incubation time, respectively. The concentration of the unidentified sugars was calculated as follows:

$$
\text { Unidentified sugars }=\text { Reducing sugars }-(\text { Glucose }+ \text { Xylose })
$$

\section{Conclusions}

Neither the catalytic efficiency on model substrates nor the thermo-stability of the individual mannanases accurately predicted their performance during lignocellulose degradation. It is apparent from this study that using the activity of glycoside hydrolases recorded on model substrates is a poor predictor of their activity on biologically-significant complex lignocellulosic substrates. This demonstrates that, in the context of natural polysaccharides, being intertwined with each other and with lignin within cell walls greatly influences the specificity of these enzymes, providing an explanation for both their complex modular structures and the large number of enzyme isoforms expressed by the same organism.

Author Contributions: Conceptualization, S.M. and B.I.P.; methodology, S.M.; validation, S.M. and B.I.P.; formal analysis, S.M.; investigation, S.M.; data curation, S.M.; writing-original draft preparation, S.M.; writing-review and editing, S.M.; visualization, S.M.; supervision, B.I.P.; project administration, S.M.; funding acquisition, B.I.P. All authors have read and agreed to the published version of the manuscript.

Funding: Financial support from the National Research Foundation (NRF) of South Africa and Rhodes University is gratefully acknowledged. Any opinion, findings and conclusions or recommendations expressed in this material are those of the author(s) and therefore the NRF and Rhodes University do not accept any liability in regard thereto.

Acknowledgments: We thank Madhavi Latha Gandla and Leif J. Jönsson at the Department of Chemistry in Umeå University, Sweden, for lignocellulosic biomass composition analysis.

Conflicts of Interest: The authors declare no conflict of interest. 


\section{References}

1. Hu, J.; Saddler, J.N. Why does GH10 xylanase have better performance than GH11 xylanase for the deconstruction of pretreated biomass? Biomass Bioenergy 2018, 110, 13-16. [CrossRef]

2. Pletschke, B.I.; Malgas, S.; Bhattacharya, A.; Bhattacharya-Shrivastava, A.; Clarke, M.D.; Mafa, M.S.; Morake, S.; Thoresen, M. Enzyme synergism: A powerful tool for decreasing enzyme loading for efficient biomass conversion. In Proceedings of the 24th European Biomass Conference and Exhibition, Amsterdam, The Netherlands, 6-9 June 2016; Volume 2016.

3. Malgas, S.; Thoresen, M.; van Dyk, J.S.; Pletschke, B.I. Time dependence of enzyme synergism during the degradation of model and natural lignocellulosic substrates. Enzym. Microb. Technol. 2017, 103, 1-11. [CrossRef] [PubMed]

4. Malgas, S.; van Dyk, J.S.; Pletschke, B.I. A review of the enzymatic hydrolysis of mannans and synergistic interactions between $\beta$-mannanase, $\beta$-mannosidase and $\alpha$-galactosidase. World J. Microbiol. Biotechnol. 2015, 31, 1167-1175. [CrossRef] [PubMed]

5. Olver, B.; Dyk, J.S.; Beukes, N.; Pletschke, B.I. Synergy between EngE, XynA and ManA from Clostridium cellulovorans on corn stalk, grass and pineapple pulp substrates. 3 Biotech 2011, 1, 187-192. [CrossRef] [PubMed]

6. Beukes, N.; Chan, H.; Doi, R.H.; Pletschke, B.I. Synergistic associations between Clostridium cellulovorans enzymes XynA, ManA and EngE against sugarcane bagasse. Enzym. Microb. Technol. 2008, 42, 492-498. [CrossRef]

7. Beukes, N.; Pletschke, B.I. Effect of alkaline pre-treatment on enzyme synergy for efficient hemicellulose hydrolysis in sugarcane bagasse. Bioresour. Technol. 2011, 102, 5207-5213. [CrossRef]

8. Ma, L.; Ma, Q.; Cai, R.; Zong, Z.; Du, L.; Guo, G.; Zhang, Y.; Xiao, D. Effect of $\beta$-mannanase domain from Trichoderma reesei on its biochemical characters and synergistic hydrolysis of sugarcane bagasse. J. Sci. Food Agric. 2017, 98, 2540-2547. [CrossRef]

9. Várnai, A.; Huikko, L.; Pere, J.; Siika-aho, M.; Viikari, L. Synergistic action of xylanase and mannanase improves the total hydrolysis of softwood. Bioresour. Technol. 2011, 102, 9096-9104. [CrossRef]

10. Agrawal, P.; Verma, D.; Daniell, H. Expression of Trichoderma reesei $\beta$-mannanase in tobacco chloroplasts and its utilization in lignocellulosic woody biomass hydrolysis. PLoS ONE 2011, 6, e29302. [CrossRef]

11. Malgas, S.; van Dyk, S.J.; Pletschke, B.I. $\beta$-Mannanase (Man26A) and $\alpha$-galactosidase (Aga27A) synergismA key factor for the hydrolysis of galactomannan substrates. Enzym. Microb. Technol. 2015, 70, 1-8. [CrossRef]

12. Von Freiesleben, P.; Spodsberg, N.; Blicher, T.H.; Anderson, L.; Jørgensen, H.; Stålbrand, H.; Meyer, A.S.; Krogh, K.B.R.M. An Aspergillus nidulans GH26 endo- $\beta$-mannanase with a novel degradation pattern on highly substituted galactomannans. Enzym. Microb. Technol. 2016, 83, 68-77. [CrossRef] [PubMed]

13. Tailford, L.E.; Ducros, V.M.-A.; Flint, J.E.; Roberts, S.M.; Morland, C.; Zechel, D.L.; Smith, N.; Bjørnvad, M.E.; Borchert, T.V.; Wilson, K.S.; et al. Understanding how diverse $\beta$-mannanases recognize heterogeneous substrates. Biochemistry 2009, 48, 7009-7018. [CrossRef] [PubMed]

14. Von Freiesleben, P.; Spodsberg, N.; Stenbæk, A.; Stålbrand, H.; Krogh, K.B.R.M.; Meyer, A.S. Boosting of enzymatic softwood saccharification by fungal GH5 and GH26 endomannanases. Biotechnol. Biofuels 2018, 11, 194. [CrossRef] [PubMed]

15. Lou, H.; Lin, M.; Zeng, M.; Cai, C.; Pang, Y.; Yang, D.; Qiu, X. Effect of Urea on the Enzymatic Hydrolysis of Lignocellulosic Substrate and Its Mechanism. Bioenergy Res. 2018, 11, 456-465. [CrossRef]

16. Ko, J.K.; Ximenes, E.; Kim, Y.; Ladisch, M.R. Adsorption of enzyme onto lignins of liquid hot water pretreated hardwoods. Biotechnol. Bioeng. 2015, 112, 447-456. [CrossRef] [PubMed]

17. Jeoh, T.; Wilson, D.B.; Walker, L.P. Effect of cellulase mole fraction and cellulose recalcitrance on synergism in cellulose hydrolysis and binding. Biotechnol. Prog. 2006, 22, 270-277. [CrossRef]

18. Liang, D.; Gong, L.; Yao, B.; Xue, X.; Qin, X.; Ma, R.; Luo, H.; Xie, X.; Su, X. Implication of a galactomannan-binding GH2 $\beta$-mannosidase in mannan utilization by Caldicellulosiruptor bescii. Biochem. Biophys. Res. Commun. 2015, 467, 334-340. [CrossRef]

19. Li, R.; Kibblewhite, R.; Orts, W.J.; Lee, C.C. Molecular cloning and characterization of multidomain xylanase from manure library. World J. Microbiol. Biotechnol. 2009, 25, 2071-2078. [CrossRef] 
20. Hägglund, P.; Eriksson, T.; Collén, A.; Nerinckx, W.; Claeyssens, M.; Stålbrand, H. A cellulose-binding module of the Trichoderma reesei $\beta$-mannanase Man5A increases the mannan-hydrolysis of complex substrates. J. Biotechnol. 2003, 101, 37-48. [CrossRef]

21. Hogg, D.; Pell, G.; Dupree, P.; Goubet, F.; Martin-Orue, S.M.; Armand, S.; Gilbert, H.J. The modular architecture of Cellvibrio japonicus mannanases in glycoside hydrolase families 5 and 26 points to differences in their role in mannan degradation. Biochem. J. 2003, 371, 1027-1043. [CrossRef]

22. Wang, X.; Li, K.; Yang, M.; Wang, J.; Zhang, J. Hydrolyzability of mannan after adsorption on cellulose. Cellulose 2016, 24, 35-47. [CrossRef]

23. Couturier, M.; Roussel, A.; Rosengren, A.; Leone, P.; Stålbrand, H.; Berrin, J.G. Structural and biochemical analyses of glycoside hydrolase families 5 and $26 \beta-(1,4)$-mannanases from Podospora anserina reveal differences upon manno-oligosaccharide catalysis. J. Biol. Chem. 2013, 288, 14624-14635. [CrossRef] [PubMed]

24. Malgas, S.; Chandra, R.; Van Dyk, J.S.; Saddler, J.N.; Pletschke, B.I. Formulation of an optimized synergistic enzyme cocktail, HoloMix, for effective degradation of various pre-treated hardwoods. Bioresour. Technol. 2017, 245, 52-65. [CrossRef] [PubMed]

25. Sluiter, J.B.; Ruiz, R.O.; Scarlata, C.J.; Sluiter, A.D.; Templeton, D.W. Compositional analysis of lignocellulosic feedstocks. 1. Review and description of methods. J. Agric. Food Chem. 2010, 58, 9043-9053. [CrossRef] [PubMed]

26. Normark, M.; Winestrand, S.; Lestander, T.A.; Jönsson, L.J. Analysis, pretreatment and enzymatic saccharification of different fractions of Scots pine. BMC Biotechnol. 2014, 14, 20. [CrossRef] [PubMed]

27. Bradford, M.M. A rapid and sensitive method for the quantitation of microgram quantities of protein utilizing the principle of protein-dye binding. Anal. Biochem. 1976, 72, 248-254. [CrossRef]

Publisher's Note: MDPI stays neutral with regard to jurisdictional claims in published maps and institutional affiliations. 